\title{
The Early Days of Personal Solar Ultraviolet Dosimetry
}

\author{
Brian Diffey
}

Dermatological Sciences, Newcastle University, Newcastle Upon Tyne NE2 4HH, UK; brian.diffey@ncl.ac.uk

Received: 1 January 2020; Accepted: 18 January 2020; Published: 22 January 2020

\begin{abstract}
In the early 1970s, environmental conservationists were becoming concerned that a reduction in the thickness of the atmospheric ozone layer would lead to increased levels of ultraviolet (UV) radiation at ground level, resulting in higher population exposure to UV and subsequent harm, especially a rise in skin cancer. At the time, no measurements had been reported on the normal levels of solar UV radiation which populations received in their usual environment, so this lack of data, coupled with increasing concerns about the impact to human health, led to the development of simple devices that monitored personal UV exposure. The first and most widely used UV dosimeter was the polymer film, polysulphone, and this review describes its properties and some of the pioneering studies using the dosimeter that led to a quantitative understanding of human exposure to sunlight in a variety of behavioral, occupational, and geographical settings.
\end{abstract}

Keywords: sun exposure; dosimetry; polysulphone; human exposure

\section{Introduction}

In the early 1970s, environmental conservationists were becoming increasingly concerned that changes in the atmospheric ozone layer might be induced by both high-flying supersonic aircraft, and by the build-up of freons and related compounds. It was believed that any reduction in the thickness of the ozone layer would lead to increased levels of ultraviolet (UV) radiation at ground level, resulting in higher population exposure to UV and accompanying subsequent harm, especially a rise in skin cancer.

At the time, no measurements had been reported on the normal levels of solar UV radiation which populations received in their usual environment, so this lack of data, coupled with increasing concerns about the impact to human health, led to the development of simple devices that monitored personal UV exposure.

\section{Fundamental Requirements of Personal Ultraviolet Dosimeters}

Whilst radiometers and spectroradiometers are used to monitor ambient solar UV radiation, these instruments are not suited to determining the UV exposure of individuals, especially at multiple sites over the body, because of their bulk and generally high cost. Ideally, UV dosimeters designed for personal use should have the following characteristics:

- The dosimeter should be easy to handle and not impose restrictions on the activities of the wearers.

- In physical dosimeters, the output electrical signal should increase linearly with irradiance and have a wide dynamic range.

- In chemical or biological dosimeters, the change produced in the system should increase linearly with UV dose. If not, the dose response curve should at least be monotonic; that is, any given dosimeter response is the result of only one radiation dose.

- The dosimeter should exhibit photoaddition; in other words, each wavelength acts independently, and the effect of polychromatic radiation is the sum of the effects of all wavelengths involved. 
- The spectral sensitivity of the dosimeter should, ideally, match the action spectrum of the photobiological effect being monitored, most commonly erythema.

- The dosimeter response should be independent of temperature and humidity, exhibit no 'dark effect' (continuing response when radiation exposure is terminated), and be stable in long-term storage.

- The dosimeter should not require laborious processing, and it should be easy to convert the physical, chemical, or biological response to a measure of UV exposure dose.

- The cost per dosimeter should be low so that large scale monitoring is feasible.

The most widely used personal UV dosimeter over the past 40 years has been the plastic film, polysulphone. The narrative that follows is told from the perspective of someone who was there at the beginning of the development of personal UV dosimeters and who has contributed to several studies on the measurement of human exposure to solar UV radiation throughout this period.

\section{The Birth of Polysulphone as a Dosimeter for Measuring Personal Solar UV Exposure}

While evaluating the weathering characteristics of the polymers polysulphone (PSP) and polyphenylene oxide (PPO), Tony Davis and colleagues, based at a UK defense establishment, found that they both darkened when exposed to UV radiation [1]. They realized the potential of these polymers as UV monitors and used PPO to continuously monitor solar ultraviolet radiation at forty sites throughout the world [2].

At a chance meeting in 1975, I suggested to Tony Davis that maybe PPO or PSP might be useful for monitoring personal exposure to UV, analogous to film badges worn by people exposed to ionizing radiation in hospital X-ray departments, for example. An important requirement for any UV dosimeter used to monitor biologically effective UV is that the wavelength response of the dosimeter should be similar to the action spectrum pertinent to the biological effect of interest, which is usually UV-induced erythema in human skin [3].

PPO film shows spectral sensitivity up to $400 \mathrm{~nm}$, unlike PSP, which is not responsive above about $340 \mathrm{~nm}$. Additionally, because PSP is about 10 times more sensitive than PPO, it was more suited for use as a personal UV dosimeter. Therefore, we focused our attention on PSP film (40 $\mu \mathrm{m}$ thick) with a view to developing the material as a possible personal dosimeter to measure exposure of the skin to UV radiation.

When exposed to UV radiation, PSP film degrades and loses tensile properties. At the same time, the initial broad absorption band in the near UV extends with dose towards the visible. As a measure of the degree of degradation of the polymer, we took the change in absorbance pre- and post-exposure measured at $330 \mathrm{~nm}\left(\Delta \mathrm{A}_{330}\right)$, as a measure of UV dose. This absorbance change was investigated as a function of incident UV exposure for wavelengths ranging from $254 \mathrm{~nm}$ to $335 \mathrm{~nm}$ [4]. The first dose-response curve, obtained for PSP film irradiation at $297 \pm 5 \mathrm{~nm}$, is shown in Figure 1. 


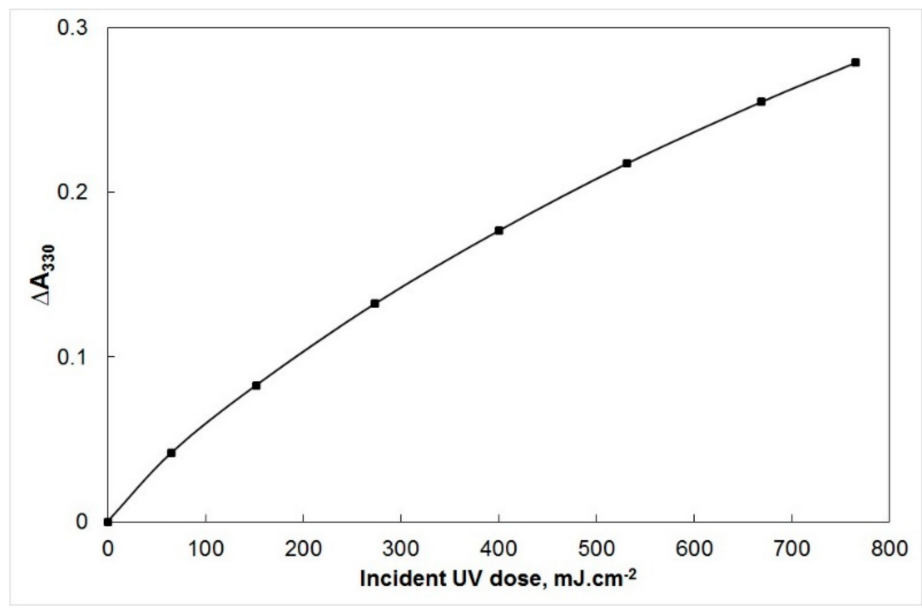

Figure 1. The first dose-response curve of polysulphone (PSP) film, showing the variation of $\Delta \mathrm{A}_{330}$ with incident ultraviolet exposure at a wavelength of $297 \mathrm{~nm}$ [4].

To derive the wavelength response of the film, the reciprocal of the dose required to produce a $\Delta \mathrm{A}_{330}$ of 0.1 at each wavelength was plotted as a function of wavelength, normalized to unity at the most sensitive wavelength (Figure 2). In Figure 2, the erythemal action spectrum of human skin [3] is compared with the spectral sensitivity of polysulphone; and although the agreement is not ideal, it is possible to allow for this, if the relative spectral distribution of the incident radiation is known (see below).

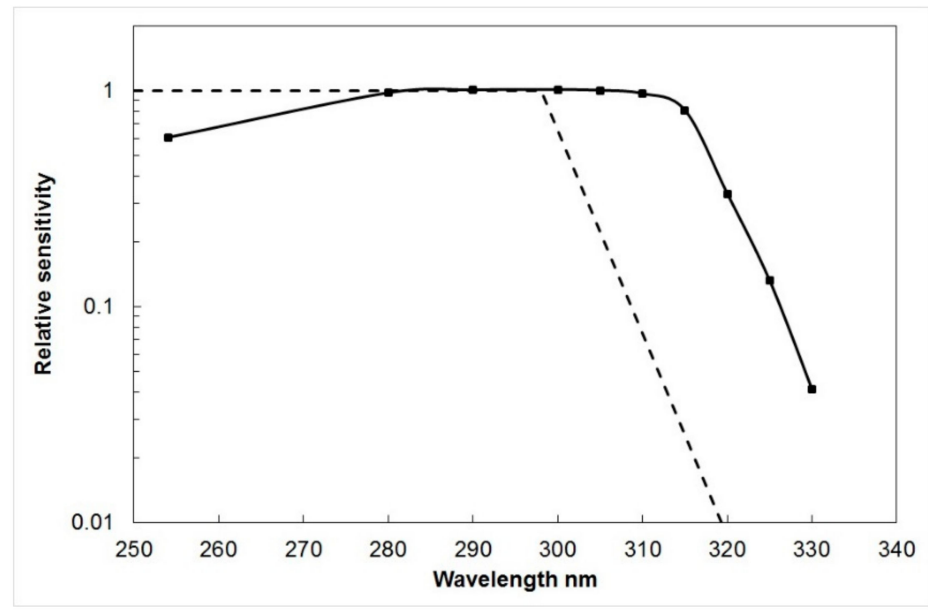

Figure 2. The spectral sensitivity of PSP film (solid curve) [4] and the erythema action spectrum (broken curve) [3].

The absorbance of PSP film before and after exposure can be measured with any standard UV spectrophotometer and takes about 5-10 s per badge, depending on the dexterity of the operator. However, the task can be tedious, especially when several hundred badges have to be processed. To address this problem, a device based on a commercial slide projector was described [5], that read and printed the absorbance of up to 60 badges at a time.

Polysulphone film largely meets the requirements for a personal dosimeter, as listed in the previous section, but there are some shortcomings. The spectral sensitivity is not ideal for a dosimeter designed to measure erythemal radiation (Figure 2); although this limitation can be accounted for, to some extent, in the calibration procedure (see below). The dynamic range is somewhat restricted as a result of saturation effects, necessitating the replacement of film badges on a daily to a weekly basis, depending on outdoor behavior of subjects. 
Finally, PSP film does exhibit a dark reaction, in that the $\Delta \mathrm{A}_{330}$ measured immediately after exposure is about $8 \%$ less than that measured $24 \mathrm{~h}$ later, and $10 \%$ less than that measured one week later [6]. However, this can be accounted for if the measurement was made at the same time after exposure, e.g., $24 \mathrm{~h}$, that was used during calibration.

\section{Calibration of Polysulphone Film as a UV Dosimeter}

Because the spectral sensitivity of PSP film is not an exact match to the erythema action spectrum (Figure 2), it is important that the badges are calibrated for each type of UV source to which they are exposed, ideally by spectroradiometric methods [6].

Most applications measure personal exposure to solar UV radiation, and Figure 3 shows the results of calibrating the film using Australian sunlight. Briefly, the spectral irradiance from 290 to $400 \mathrm{~nm}$, in steps of $1 \mathrm{~nm}$, was measured using a scanning spectroradiometer on a flat, unshaded surface every half hour throughout a day in spring in Queensland, and a summer's day in Victoria. Pairs of PSP dosimeters, placed adjacent to the spectroradiometer, were exposed for varying combinations of time intervals during the day. By this means, it was possible to expose several pairs of dosimeters to approximately the same erythemally effective UV dose, but for differing time periods.

The following day, the optical absorbance of each dosimeter at $330 \mathrm{~nm}$ was determined in a spectrophotometer, and the difference $\left(\Delta \mathrm{A}_{330}\right)$ between this post-exposure absorbance and the absorbance determined prior to the exposure was determined for each dosimeter. The erythemally effective dose received by a given film badge during a specified time interval was estimated from the spectral irradiance determined every $30 \mathrm{~min}$, combined with the erythema action spectrum [3]. The observed $\Delta \mathrm{A}_{330}$ for each film badge is plotted in Figure 3.

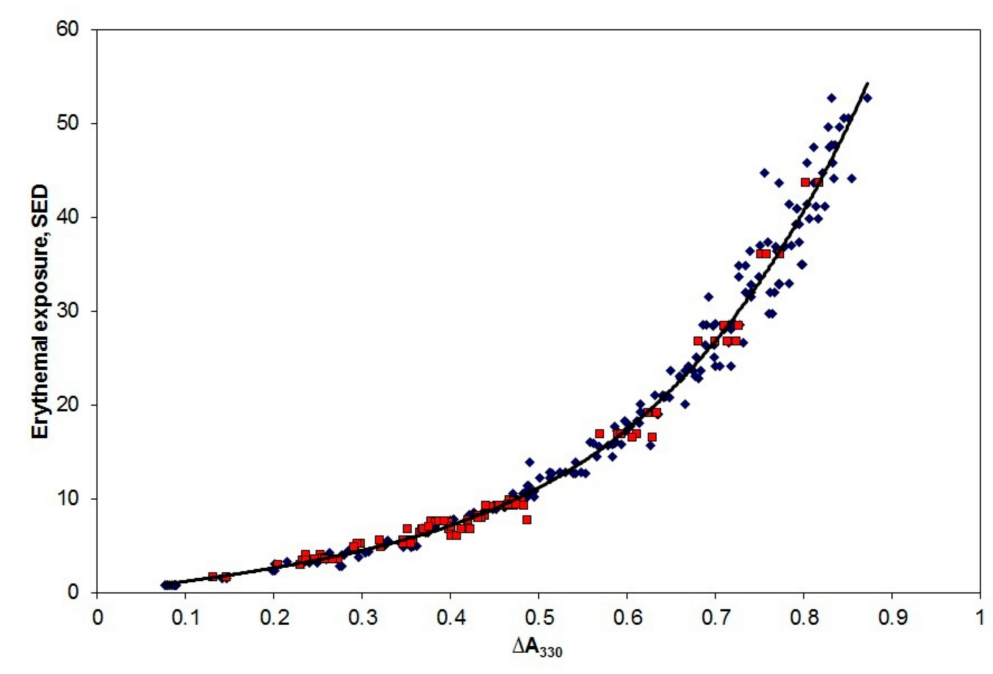

Figure 3. Exposure of PSP film badges to sunlight in Queensland (blue diamonds) and Victoria (red squares). The solid black curve is a quartic fit to the data.

The solid line is an equation of the form:

$$
\text { Erythemal dose }(\mathrm{SED})=10.7\left[\Delta \mathrm{A}_{330}\right]+14.3\left[\Delta \mathrm{A}_{330}\right]^{2}-26.4\left[\Delta \mathrm{A}_{330}\right]^{3}+89.1\left[\Delta \mathrm{A}_{330}\right]^{4}
$$

The erythemal dose is expressed in SED (Standard Erythema Dose), where 1 SED is equivalent to an erythemal effective radiant exposure of $100 \mathrm{Jm}^{-2}$ [3].

The mismatch between the spectral response of PSP and the erythema action spectrum (Figure 2) will lead to calibration errors that are a function of solar altitude and ozone amount. In principle, it is possible to correct such errors using the procedures described by Seckmeyer et al. [7]. Without such 
corrections, however, it is important to determine the calibration curve under similar atmospheric conditions to the exposure of population groups [8].

\section{Using Polysulphone Film as a Personal UV Dosimeter}

The very first PSP film badges were made by securing rectangles of the film, approximately $40 \mu \mathrm{m}$ thick, into standard $35 \mathrm{~mm}$ transparency mounts, resulting in a film badge of $50 \times 50 \mathrm{~mm}$ with an open aperture of $25 \times 35 \mathrm{~mm}$ (Figure 4a). These mounts were slotted into specially constructed metal holders which were fastened by a safety pin to the lapel site of volunteers as a proxy for facial solar UV exposure. By comparison, personal ionizing radiation monitors utilizing photographic film are normally worn on the torso to give an indication of whole-body dose.

These film badges were not especially liked by volunteers due to their prominent size and so were soon replaced with a cardboard holder measuring $30 \mathrm{~mm} \times 30 \mathrm{~mm}$, with the film mounted in a central aperture of $10 \mathrm{~mm} \times 15 \mathrm{~mm}$ (Figure $4 \mathrm{~b}$ ). With this single aperture badge, only a small fraction of the exposed surface area is used for spectroradiometry. In order to increase reliability, Gibbs et al. [9] described a film badge of the same overall dimension incorporating four circular apertures, each of 6 $\mathrm{mm}$ diameter (Figure $4 \mathrm{c}$ ).

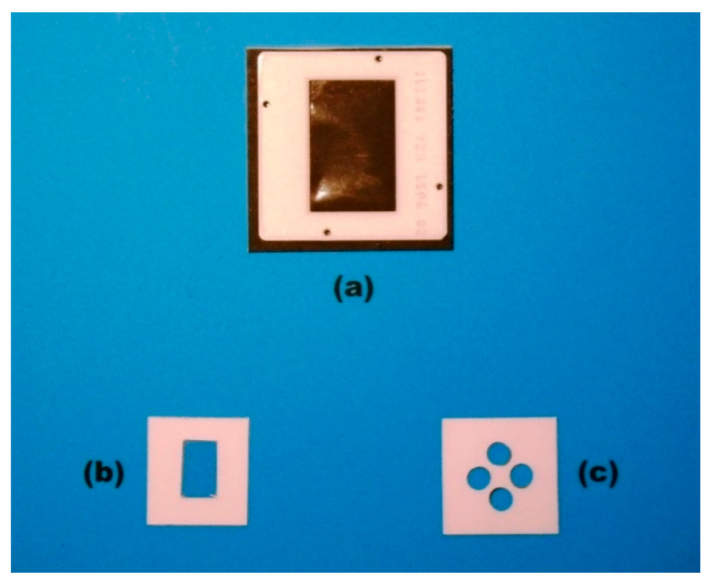

Figure 4. Three different PSP film badge holders.

However, these four-aperture mounts never became popular due to the increased time required to measure the pre- and post-exposure absorbances, and so for the vast majority of studies of personal exposure reported in the literature, the single aperture mount (Figure $4 \mathrm{~b}$ ) has been the film badge of choice.

\section{Pioneering Studies of Human Exposure to Solar UV}

The first study on exposure of human subjects to solar UV was reported by Challoner et al. [10], where they compared the exposure received by nine laboratory workers, two hospital gardeners, and six geriatric in-patients, all working or staying in a London hospital. The geriatric patients were divided into those able to sit in the sun on a balcony, and those restricted to the ward. The observations were made during a two-week period in June and July 1975. All film badges were worn by the volunteer subjects on the lapel site.

The results showed that the laboratory workers received about $5 \%$ of the ambient weekly dose, and half of this was during leisure activities on the weekend; whereas the gardeners at work received just over $10 \%$ of the ambient weekly UV, defined as the exposure on an unshaded, horizontal surface. In fact, the laboratory workers during the weekend showed mean daily exposures comparable to that of the gardeners at work. The geriatric patients received doses ranging from about $0.1 \%$ of the ambient for those who were restricted to the ward, to $9 \%$ for those who had access to the balcony [10]. 
A parallel investigation using PSP film on a larger group of office workers over a longer time interval was carried out in Bristol, UK [11]. About 30 office personnel were monitored for eight fortnightly periods during the summer, autumn, winter, and spring. The individuals received about $3-4 \%$ of ambient UV, and there was no noticeable variation in this fraction with season.

All the groups in these two studies showed relatively high variance, due to factors such as propensity for spending time outdoors, positioning of the film badges, posture, and behavior.

\section{Applications of Polysulphone Film Dosimetry}

Following the initial studies described above, personal UV dosimetry using PSP film quickly caught on. In the 1980s and 1990s, there were several publications on the personal solar UV exposure of people, from countries including Sweden, Australia, and the USA, engaging in various occupations and leisure pursuits [12-26], or exhibiting either idiopathic [27] or drug-induced [28] photosensitivity.

Sun exposure in childhood is believed to be a critical factor in the risk of developing skin cancer later in life, so it was not surprising that a number of studies were undertaken to estimate the magnitude of solar UV exposure in children, ranging from babies to adolescents [29-38].

Studies were not limited to natural sun exposure, but extended into exposure from artificial sources of UV radiation, such as industrial light sources [39], welding arcs [40-42], phototherapy units for skin disease $[12,19,20,43,44]$, and banks of UVB lamps, designed to produce vitamin D in elderly people [45-47].

Further details of these, and more recent studies, can be found in excellent reviews on personal solar UV exposure in both children [48] and adults [49].

\section{Anatomical Distribution of Solar UV Radiation}

The small size of PSP film dosimeters means that they are particularly suited to measure the anatomical distribution of solar UV radiation, and a number of studies have addressed this issue on both mannequins and living subjects [16,50-53]. Of note, are a few studies that recorded solar UV exposure around the eye [54-56], and even one study that recorded the anatomical distribution of UV radiation at 17 sites on the surface of horses both outdoors, and underneath UV solaria indoors [57].

\section{Other Types of Personal UV Dosimeter}

Whilst PSP film remains the most widely used personal UV dosimeter, other systems have been developed with varying degrees of success, and these are briefly described below.

\subsection{Plastic Films Incorporating Photosensitizing Drugs}

In field studies of drug-induced photosensitivity, the possibility of using a dosimeter which incorporates the relevant drug is an attractive proposition. To this end, several drugs which are known to have photosensitizing effects in humans have been incorporated as the chromophore in a polyvinyl chloride (PVC) film. Photoactive drugs which have been used in this way include phenothiazine [58], 8-methoxypsoralen [59], nalidixic acid [60], and benoxaprofen [61].

As an example, film badges that incorporated the drug 8-methoxypsoralen as the chromophore [58], were used to monitor the personal solar UVA doses received by patients undergoing oral psoralen photochemotherapy (PUVA) for psoriasis [62].

\subsection{Diazo Systems}

Diazo systems, which are based on diazonium compounds, are one of the oldest photochemical non-silver processes. The two fundamental properties of the diazo type process which make it suitable for use as a UV dosimeter are its capacity to be decomposed by UV radiation, and the ability of the undecomposed diazonium compound to couple with a color former to produce a stable image. 
Diazonium compounds are sensitive principally to the UVA and blue regions of the spectrum. Their spectral sensitivity, together with the simplicity, economy, and convenience of the diazo system, have led to their use as film badge dosimeters for UVA and blue radiation $[63,64]$.

\subsection{Photosensitive Papers}

One drawback of the film dosimeters described above, is that they require laboratory equipment to facilitate readout. An alternative approach is to use a system whereby the photochemical process initiates a color change, so that visual comparisons with stable printed color standards enable the user to obtain a reasonably accurate and continuously readable integrated measure of his exposure to UV radiation. An example of a dosimeter based on this principle was described by Zweig and Henderson [65]. This dosimeter is a polycarbonate film matrix incorporating a chromophore which converts to a red photoproduct following exposure to UV of wavelengths less than $350 \mathrm{~nm}$. The depth of the red color developed depends solely on the radiant exposure.

Another type of dosimeter is based on the reversible color change of photochromic aziridine formulations [66]. The colorless aziridine undergoes isomerization following UV exposure, to form the blue-colored azomethine ylide.

Photosensitive papers have formed the basis of dosimeters designed for consumer use whilst sunbathing [67]. The main drawback of photosensitive papers is that, at best, they provide a semi-quantitative estimate of exposure.

\subsection{Thermoluminescent Materials}

Several thermoluminescent (TL) materials have been investigated as possible UV dosimeters. These have included LiF:Mg, $\mathrm{CaF}_{2}: \mathrm{Dy}, \mathrm{CaF}_{2}: \mathrm{Mn}, \mathrm{Al}_{2} \mathrm{O}_{3}, \mathrm{LiF}: \mathrm{Mg}, \mathrm{CaSO}_{4}: \mathrm{Dy}$ [68], $\mathrm{CaF}_{2}: \mathrm{TB}_{4} \mathrm{O}_{7}$ [69], and semiconductor-doped Vycor glass [70]. TL materials have never found established roles as UV dosimeters.

\subsection{Polycarbonate Plastic}

On exposure to UV, the transparent plastic, CR-39 (allyl diglycol carbonate), alters its optical properties. These changes are the basis of its use as a UV dosimeter [71]. After exposure, the plastic is etched in $6 \mathrm{~N} \mathrm{KOH}$ at $80{ }^{\circ} \mathrm{C}$ for $3 \mathrm{~h}$, rinsed, and allowed to dry. The degree of UV dose-dependent front surface damage, visible as opacification, is quantified by measuring the transmission at $700 \mathrm{~nm}$. A comparison of CR-39 with polysulphone film [72] has shown the latter to be a more reliable UV dosimeter.

\subsection{Biological Systems}

The bacteriophage, T7, has been described for use as a UV biosensor [73]. It has been used to monitor ambient UV radiation [74], and when combined with an appropriate optical filter, a spectral response similar to the action spectrum for erythema in human skin can be achieved [75].

\subsection{Electronic Dosimeters}

The use of integrating dosimeters, such as all of those described above, does not permit an assessment of the magnitude and change in exposure rate during the measurement period. However, the availability of miniature electro-optical UV sensors meant that it was possible to construct small UV detectors that can be electrically coupled to a data logger clipped to clothing or worn on the wrist. By this means, it is possible to sample UV irradiance in short time intervals, over many hours.

An early example of an electronic dosimeter that incorporated a GaP photodiode, and an ultraviolet transmitting, visible light absorbing optical filter coupled to a commercially available data logger, was described by Diffey and Saunders [76]. The detector was clipped to a waistband, and the data logger, which was rather bulky, was carried in a trouser pocket. The instrument was used to monitor 
variations in exposure rate that occurred during outdoor activities with differing weather conditions. The results demonstrated clearly that behavior outdoors can be a more dominant factor in determining personal UV exposure, than ambient levels [76].

Improvements in electro-optical technology and miniaturization led to other electronic UV dosimeters [77-79]. One such device, termed the SunSaver [76], that was developed by scientists at Bispebjerg Hospital in Copenhagen, has been used in several studies of both occupational and non-occupational sun exposure [80].

\section{Conclusions}

Environmental concerns about damage to the stratospheric ozone layer were the impetus that led to the development of personal UV dosimeters from the 1970s onwards. The most successful and widely used of these is the polymer film, polysulphone. This film dosimeter combined ease of use with low cost and has resulted in several studies of human exposure to both sunlight and artificial sources of UV radiation, in groups of subjects ranging from babies to elderly people. The results obtained from these studies now provide an extensive dataset of human UV exposure levels in a wide range of settings, both geographical and behavioral.

Funding: This research received no external funding.

Conflicts of Interest: The authors declare no conflict of interest.

\section{References}

1. Davis, A.; Gordon, D.; Howell, G.V. Explosives Research and Development Establishment Reports; Nos. 141, 199 and 197; Ministry of Defence: New Delhi, India, 1975.

2. Davis, A.; Deane, G.H.W.; Gordon, D.; Howell, G.V.; Ledbury, K.J. A worldwide programme for the continuous monitoring of solar UV radiation using polyphenylene oxide film. J. Appl. Polym. Sci. 1976, 20, 1165-1174. [CrossRef]

3. Commission Internationale de l'Eclairage. Erythema Reference Action Spectrum and Standard Erythema Dose; CIE S007E-1998; CIE Central Bureau: Vienna, Austria, 1998.

4. Davis, A.; Deane, G.; Disffey, B. Possible dosimeter for ultraviolet radiation. Nature 1976, 261, 169-170. [CrossRef] [PubMed]

5. Pepper, M.G.; Diffey, B.L. Automatic read-out device for ultraviolet radiation polymer film dosimeters. Med. Bio. Eng. Comput. 1980, 18, 467-473. [CrossRef] [PubMed]

6. Diffey, B.L. Ultraviolet radiation dosimetry with polysulphone film. In Radiation Measurement in Photobiology; Diffey, B.L., Ed.; Academic Press: London, UK, 1989; pp. 135-139.

7. Seckmeyer, G.; Bais, A.; Bernhard, G.; Blumthaler, M.; Booth, C.R.; Lantz, K.; McKenzie, R.L. Instruments to Measure Solar Ultraviolet Irradiance. Part 2: Broadband Instruments Measuring Erythemally Weighted Solar Irradiance; Global Atmosphere Watch, Report No. 164; World Meteorological Organization: Geneva, Switzerland, 2008.

8. Casal, G.R.; Borra, M.; Colosimo, A.; Colucci, M.; Militello, M.; Siani, A.M.; Sisto, R. Variability among polysulphone calibration curves. Phys. Med. Biol. 2006, 51, 4413-4427. [CrossRef]

9. Gibbs, N.K.; Young, A.R.; Corbett, M.F. Personal solar UVR exposure: A method of increasing the reliability of measurements made with film badge dosimeters. Photodermatology 1984, 1, 133-136.

10. Challoner, A.V.J.; Corless, D.; Davis, A.; Deane, G.H.W.; Diffey, B.L.; Gupta, S.P.; Magnus, I.A. Personnel monitoring of exposure to ultraviolet radiation. Clin. Exp. Dermatol. 1976, 1, 175-179. [CrossRef]

11. Leach, J.F.; McLeod, V.E.; Pingstone, A.R.; Davis, A.; Deane, G.H.W. Measurement of the ultraviolet doses received by office workers. Clin. Exp. Dermatol. 1978, 3, 77-79. [CrossRef]

12. Diffey, B.L.; Larkö, O.; Swanbeck, G. UV-B doses received during different outdoor activities and UV-B treatment of psoriasis. Br. J. Dermatol. 1982, 106, 279-285. [CrossRef]

13. Gies, H.P.; Herlihy, E.; Rivers, J. Personal dosimetry of solar UVB using polysulphone film. Proc. IRPA 8 Congr. Montr. 1992, 1, 791-794. 
14. Snellman, E.; Jansen, C.T.; Lauharanta, J.; Kolari, P. Solar ultraviolet (UV) radiation and UV doses received by patients during four-week climate therapy periods in the Canary Islands. Photodermatol. Photoimmunol. Photomed. 1992, 9, 40-43.

15. Kimlin, M.G.; Parisi, A.V.; Wong, J.C.F. Quantification of personal solar UV exposure of outdoor workers, indoor workers and adolescents at two locations in Southeast Queensland. Photodermatol. Photoimmunol. Photomed. 1998, 14, 7-11. [CrossRef] [PubMed]

16. Holman, C.D.J.; Gibson, I.M.; Stephenson, M.; Armstrong, B.K. Ultraviolet irradiation of human body sites in relation to occupation and outdoor activity: Field studies using personal UVR dosimeters. Clin. Exp. Dermatol. 1983, 8, 269-277. [CrossRef] [PubMed]

17. Parisi, A.V.; Meldrum, L.R.; Kimlin, M.G.; Wong, J.C.F.; Aitken, J.; Mainstone, J.S. Evaluation of differences in ultraviolet exposure during weekend and weekday activities. Phys. Med. Biol. 2000, 45, 2253-2262. [CrossRef]

18. Kimlin, M.G.; Wong, J.C.F.; Parisi, A.V. Simultaneous comparison of the personal UV exposure of two human groups at different altitudes. Health Phys. 1998, 74, 429-434. [CrossRef] [PubMed]

19. Schothorst, A.A.; Slaper, H.; Schouten, R.; Suurmond, D. UVB doses in maintenance psoriasis phototherapy versus solar UVB exposure. Photodermatology 1985, 2, 213-220.

20. Larkö, O.; Diffey, B.L. Natural UV-B radiation received by people with outdoor, indoor and mixed occupations and UV-B treatment of psoriasis. Clin. Exp. Dermatol. 1983, 8, 279-285. [CrossRef]

21. Gies, H.P.; Roy, C.R.; Toomey, S.; MacLennan, R.; Watson, M. Solar UVR exposures of three groups of outdoor workers on the Sunshine Coast, Queensland. Photochem. Photobiol. 1995, 62, 1015-1021. [CrossRef]

22. Slaper, H. Skin Cancer and UV Exposure: Investigations on the Estimation of Risks. PhD Thesis, University of Utrecht, Utrecht, The Netherlands, 1987.

23. Webb, A.R. Solar ultraviolet radiation and vitamin D synthesis in man. PhD Thesis, University of Nottingham, Nottingham, UK, 1985.

24. Knuschke, P.; Barth, J. Biologically weighted personal UV dosimetery. J. Photochem. Photobiol. 1996, 36, 77-83. [CrossRef]

25. Herlihy, E.; Gies, H.P.; Roy, C.R.; Jones, M. Personal dosimetry of solar UVR for different outdoor activities. Photochem. Photobiol. 1994, 60, 288-294. [CrossRef]

26. Diffey, B.L.; Roscoe, A.H. Exposure to solar ultraviolet radiation in flight. Aviat. Space Environ. Med. 1990, 61, 1032-1035.

27. Corbett, M.F.; Hawk, J.L.M.; Herxheimer, A.; Magnus, I.A. Controlled therapeutic trials in polymorphic light eruption. Br. J. Dermatol. 1982, 107, 571-581. [CrossRef] [PubMed]

28. Corbett, M.F.; Davis, A.; Magnus, I.A. Personnel radiation dosimetry in drug photosensitivity: Field studies of patients on phenothiazine therapy. Br. J. Dermatol. 1978, 98, 39-46. [CrossRef] [PubMed]

29. Rosenthal, F.S.; Lew, R.A.; Rouleau, L.J.; Thomson, M. Ultraviolet exposure to children from sunlight: A study using personal dosimetry. Photodermatol. Photoimmunol. Photomed. 1990, 7, 77-81.

30. Melville, S.K.; Rosenthal, F.S.; Luckmann, R.; Lew, R.A. Quantitative ultraviolet skin exposure in children during selected outdoor activities. Photodermatol. Photoimmunol. Photomed. 1991, 8, 99-104.

31. Diffey, B.L.; Gibson, C.J.; Haylock, R.; McKinlay, A.F. Outdoor ultraviolet exposure of children and adolescents. Br. J. Dermatol. 1996, 134, 1030-1034. [CrossRef]

32. Diffey, B.L.; Gies, H.P. The confounding influence of sun exposure in melanoma. Lancet 1998, 351, 1101-1102. [CrossRef]

33. Gies, H.P.; Roy, C.R.; Toomey, S.; MacLennan, R.; Watson, M. Solar UVR exposures of primary school children at three locations in Queensland. Photochem. Photobio. 1998, 68, 78-83. [CrossRef]

34. Moise, A.F.; Büttner, P.G.; Harrison, S.L. Sun exposure at school. Photochem. Photobiol. 1999, 70, $269-274$. [CrossRef]

35. Moise, A.F.; Gies, H.P.; Harrison, S.L. Estimation of the annual solar UVR exposure dose of infants and small children in tropical Queensland, Australia. Photochem. Photobiol. 1999, 69, 457-463. [CrossRef]

36. Moise, A.F.; Harrison, S.L.; Gies, H.P. Solar ultraviolet radiation exposure of infants and small children. Photodermatol. Photoimmunol. Photomed. 1999, 15, 109-114. [CrossRef]

37. O'Riordan, D.L.; Stanton, W.R.; Eyeson-Annan, M.; Gies, P.; Roy, C. Correlations between reported and measured ultraviolet radiation exposure of mothers and young children. Photochem. Photobiol. 2000, 71, 60-64. [CrossRef] 
38. Parisi, A.V.; Meldrum, L.R.; Wong, J.C.F.; Aitken, J.; Fleming, R.A. Effect of childhood and adolescent ultraviolet exposures on cumulative exposure in South East Queensland schools. Photodermatol. Photoimmunol. Photomed. 2000, 16, 19-24. [CrossRef] [PubMed]

39. Diffey, B.L.; Larkö, O.; Meding, B.; Edeland, H.G.; Wester, U. Personal monitoring of exposure to ultraviolet radiation in the car manufacturing industry. Ann. Occup. Hyg. 1986, 30, 163-170. [PubMed]

40. Shehade, S.A.; Roberts, P.J.; Diffey, B.L.; Foulds, I.S. Photodermatitis due to spot welding. Br. J. Dermatol. 1987, 117, 117-119. [CrossRef]

41. Barth, C.; Knuschke, P.; Barth, J. UV-Strahlenbelastung in der Umgebung von Schweißarbeitsplätzen. Zeitschrift für die gesamte Hygiene und ihre Grenzgebiete 1990, 36, 654-655.

42. Tenkate, T.D.; Collins, M.J. Personal ultraviolet radiation exposure of workers in a welding environment. Am. Indust. Hyg. Assoc. J. 1997, 58, 33-38. [CrossRef]

43. Jekler, J.; Diffey, B.L.; Larkö, O. Ultraviolet radiation dosimetry in phototherapy for atopic dermatitis. J. Am. Acad. Dermatol. 1990, 23, 49-51. [CrossRef]

44. Larkö, O.; Diffey, B.L. Occupational exposure to ultraviolet radiation in dermatology departments. Br. J. Dermatol. 1986, 114, 479-484. [CrossRef]

45. Corless, D.; Gupta, S.P.; Switala, S.; Barragry, J.M.; Boucher, B.J.; Cohen, R.D.; Diffey, B.L. Response of Plasma-25-hydroxyvitamin D to ultraviolet irradiation in long-stay geriatric patients. Lancet 1978, 312, 649-651. [CrossRef]

46. Toss, G.; Andersson, R.; Diffey, B.L.; Fall, P.A.; Larkö, O.; Larsson, L. Oral vitamin D and ultraviolet radiation for the prevention of vitamin D deficiency in the elderly. Acta Med. Scand. 1982, 212, 157-161. [CrossRef]

47. Chuck, A.; Todd, J.; Diffey, B.L. Subliminal ultraviolet-B irradiation for the prevention of vitamin D deficiency in the elderly: A feasibility study. Photodermatol. Photoimmunol. Photomed. 2001, 17, 168-171. [CrossRef] [PubMed]

48. Wright, C.; Reeder, A.I. Youth solar ultraviolet radiation exposure, concurrent activities and sun-protective practices: A review. Photochem. Photobiol. 2005, 81, 1331-1342. [CrossRef] [PubMed]

49. Schmalwieser, A.W.; Siani, A.M. Review on nonoccupational personal solar UV exposure measurements. Photochem. Photobiol. 2018, 94, 900-915. [CrossRef]

50. Diffey, B.L.; Kerwin, M.; Davis, A. The anatomical distribution of sunlight. Br. J. Dermatol. 1977, 97, 407-410. [CrossRef]

51. Diffey, B.L.; Tate, T.J.; Davis, A. Solar dosimetry of the face: The relationship of natural ultraviolet radiation exposure to basal cell carcinoma localisation. Phys. Med. Biol. 1979, 24, 931-939. [CrossRef]

52. Airey, D.K.; Wong, J.C.F.; Fleming, R.A. A comparison of human- and headform based measurements of solar ultraviolet B dose. Photodermatol. Photoimmunol. Photomed. 1995, 11, 155-158. [CrossRef]

53. Kimlin, M.G.; Parisi, A.V.; Wong, J.C.F. The facial distribution of erythemal ultraviolet in south-east Queensland. Phys. Med. Biol. 1998, 43, 231-240. [CrossRef]

54. Rosenthal, F.S.; Safran, M.; Taylor, H.R. The ocular dose of ultraviolet radiation from sunlight exposure. Photochem. Photobiol. 1985, 42, 163-171. [CrossRef]

55. Gies, P.; Roy, C.; Elliott, G. The anatomical distribution of solar UVR with emphasis on the eye. In Proceedings of the Seventh International Congress of the International Radiation Protection Association; Pergamon Press: Sydney, Australia, 1988; pp. 341-344.

56. Lindgren, G.; Diffey, B.L.; Larkö, O. Basal cell carcinoma of the eyelids and solar ultraviolet radiation exposure. Br. J. Ophthalmol. 1998, 82, 1412-1415. [CrossRef]

57. Keck, G.; Kasper, I.; Schauberger, G.; Cabaj, A. Biological effects of UV-irradiation of horses with artificial UV-sources. In Human Exposure to Ultraviolet Radiation: Risk and Regulations; Passchier, W.F., Bosnjakovic, B.F.M., Eds.; Elsevier: Amsterdam, The Netherlands, 1987; pp. 71-76.

58. Diffey, B.L.; Davis, A.; Johnson, M.; Harrington, T.R. A dosimeter for long wave ultraviolet radiation. Br. J. Dermatol. 1977, 97, 127-130. [CrossRef]

59. Diffey, B.L.; Davis, A. A new dosimeter for the measurement of natural ultraviolet radiation in the study of photodermatoses and drug photosensitivity. Phys. Med. Biol. 1978, 23, 318-323. [CrossRef] [PubMed]

60. Tate, T.J.; Diffey, B.L.; Davis, A. An ultraviolet radiation dosimeter based on the photosensitising drug nalidixic acid. Photochem. Photobiol. 1980, 31, 27-30. [CrossRef]

61. Diffey, B.L.; Oliver, I.; Davis, A. A personal dosimeter for quantifying the biologically-effective sunlight exposure of patients receiving benoxaprofen. Phys. Med. Biol. 1982, 27, 1507-1513. [CrossRef] [PubMed] 
62. Moseley, H.; Diffey, B.L.; Marks, J.M.; Mackie, R.M. Personal solar UV-A doses received by patients undergoing oral psoralen photochemotherapy for psoriasis. Br. J. Dermatol. 1981, 105, 573-577. [CrossRef]

63. Jackson, S.A. A film badge dosimeter for UVA radiation. J. Biomed. Eng. 1980, 2, 63-64. [CrossRef]

64. Moseley, H.; Robertson, J.; O'Donoghue, J. The suitability of diazochrome KBL film for UV dosimetry. Phys. Med. Biol. 1984, 29, 679-685. [CrossRef]

65. Zweig, A.; Henderson, W.A., Jr. A photochemical mid-ultraviolet dosimeter for practical use as a sunburn dosimeter. Photochem. Photobiol. 1976, 24, 543-549. [CrossRef]

66. Fanselow, D.L.; Pathak, M.A.; Crone, M.A.; Ersfield, D.A.; Raber, P.B.; Trancik, R.J.; Dahl, M.V. Reusable ultraviolet monitors: Design, characteristics and efficacy. J. Am. Acad. Dermatol. 1983, 9, 714-724. [CrossRef]

67. Moseley, H.; Mackie, R.M.; Ferguson, J. The suitability of Suncheck patches and Tanscan cards for monitoring the sunburning effectiveness of sunlight. Br. J. Dermatol. 1993, 128, 75-78. [CrossRef]

68. Noha, A.M.; Amina, Y.M.; Mahata, R.H.; Bradley, D.A. Investigation of some commercial TLD chips/discs as UV dosimeters. Rad. Phys. Chem. 2001, 61, 497-499. [CrossRef]

69. Otaki, H.; Kido, H.; Hiratsuka, A.; Fukuda, A.Y.; Takeuchi, N. Estimation of UV radiation dose using CaF2:Tb407 as a thermoluminescence dosimeter. J. Mater. Sci. Lett. 1994, 13, 1267-1269. [CrossRef]

70. Justus, B.L.; Huston, A.L. Ultraviolet dosimetry using thermoluminescence of semiconductor-doped Vycor glass. Appl. Phys. Lett. 1995, 67, 1179-1181. [CrossRef]

71. Wong, C.F.; Fleming, R.; Carter, S.J. A new dosimeter for ultraviolet B radiation. Photochem. Photobiol. 1989, 50, 611-615. [CrossRef]

72. Sydenham, M.M.; Collins, M.J.; Hirst, L.W. The effectiveness of poly(allyl diglycol carbonate) (CR-39) for low-dose solar ultraviolet dosimetry. Photochem. Photobiol. 1994, 59, 58-65.

73. Rontó, G.; Gáspár, S.; Bérces, A. Phage T7 in biological UV dose measurement. J. Photochem. Photobiol. 1992, 12, 285-294. [CrossRef]

74. Rontó, G.; Gáspár, S.; Gróf, P.; Bérces, A.; Gugolya, Z. Ultraviolet dosimetry in outdoor measurements based on bacteriophage T7 as a biosensor. Photochem. Photobiol. 1994, 59, 209-214. [CrossRef]

75. Quintern, L.E.; Furusawa, Y.; Fukutsu, K.; Holtschmidt, H. Characterization and application of UV detector spore films: The sensitivity curve of a new detector system provides good similarity to the action spectrum for UV-induced erythema in human skin. J. Photochem. Photobiol. 1997, 37, 158-166. [CrossRef]

76. Diffey, B.L.; Saunders, P.J. Behaviour outdoors and its effect on personal ultraviolet exposure rate measured using a portable datalogging dosimeter. Photochem. Photobiol. 1995, 61, 615-618. [CrossRef]

77. Heydenreich, J.; Wulf, H.C. Miniature personal electronic UVR dosimeter with erythema response and time-stamped readings in a wristwatch. Photochem. Photobiol. 2005, 81, 1138-1144. [CrossRef]

78. Allen, M.; McKenzie, R. Enhanced UV exposure on a ski-field compared with exposures at sea level. Photochem. Photobiol. Sci. 2005, 4, 429-437. [CrossRef]

79. Naggar, S.A.; Gustat, H.; Magister, H.; Rochlitzer, R. An electronic personal UV-B-dosimeter. J. Photochem. Photobiol. B Biol. 1995, 31, 83-86. [CrossRef]

80. Thieden, E. Sun exposure behaviour among subgroups of the Danish population. Dan. Med. Bull. 2008, 55, 47-68. [PubMed]

(C) 2020 by the author. Licensee MDPI, Basel, Switzerland. This article is an open access article distributed under the terms and conditions of the Creative Commons Attribution (CC BY) license (http://creativecommons.org/licenses/by/4.0/). 